\title{
ASSESSMENT OF THE INDOOR ENVIRONMENT AND IMPLICATIONS FOR HEALTH IN ROMA VILLAGES IN SLOVAKIA AND ROMANIA
}

\author{
Marek Majdan', Alexandru Coman², Eva Gallová1, Janka Duricová1, Daniela Kállayová1, Mária Kvaková1, \\ L'uboš Bošák' \\ ${ }^{1}$ Department of Public Health, Faculty of Health Care and Social Work, Trnava University, Trnava, Slovakia \\ ${ }^{2}$ Centre for Health Policy and Public Health, Babes-Bolyai University, Cluj-Napoca, Romania
}

\section{SUMMARY}

Objectives: The objective of this paper is to provide information on indoor air quality and on the quality of the broader indoor environment of the houses in Roma villages in Slovakia and Romania and to discuss possible implications for health.

Methods: Indoor air was sampled in 11 houses in a Romanian Roma village and in 19 houses in a Slovakian Roma village. Levels of Carbon Monoxide (CO), Carbon Dioxide $\left(\mathrm{CO}_{2}\right)$, total particulate matter (PM), temperature and humidity were measured. A questionnaire and a checklist were used to obtain additional information on the indoor environment and behavioural factors. We have sampled the same houses in winter and in summer.

Results: Levels of $\mathrm{CO}$ and $\mathrm{CO}_{2}$ were higher in winter in both countries as compared to summer. The limit value of $10 \mathrm{mg} / \mathrm{m}^{3} \mathrm{CO}$ was exceeded in a few cases in both countries. In general, levels of $\mathrm{CO}, \mathrm{CO}_{2}$ and $\mathrm{PM}$ were higher in Romania. Further environmental and behavioural hazards such as indoor smoking, pets inside or lack of ventilation were found. The reported self-perceived quality of the indoor environment was poor in many aspects.

Conclusions: Our findings of $\mathrm{CO}, \mathrm{CO}_{2}$ and PM levels suggest that indoor air pollution in Roma settlements has the potential to be a health threat. The fact that the inhabitants spend a relatively long time inside the houses and that a number of additional environmental and behavioural hazards were identified by our study emphasizes the importance of the indoor air quality for health and thus priority attention should be paid to these issues by health authorities and researchers. Further research is essential and study designs must consider cultural background and specific characteristics of the community, especially in order to obtain valid data on health outcomes.

Key words: indoor air quality, housing, Roma population, health, biomass fuel

Address for correspondence: Marek Majdan, Department of Public Health, Faculty of Health Care and Social Work, Trnava University, Hornopotocna 23, 91843, Trnava, Slovakia. E-mail: mmajdan@truni.sk

\section{INTRODUCTION}

The health of the Roma minority in Central and Eastern European countries is increasingly becoming a public health concern across the region. Most of the research conducted in this area is focused on communicable diseases and genetic predispositions (1, 2). However, recent research highlights the impact of the socioeconomic determinants of health in this ethnic minority living in Central and Eastern European countries such as Slovakia, Hungary or the Czech Republic. A study conducted on the Roma minority in Hungary (3) concluded that tackling the socioeconomic predictors of their poor health along with educational and health promotion interventions is necessary to improve their health. Skodova et al. (4) in her Slovakian study of social and psychosocial predictors of coronary health amongst Roma demonstrated that the socioeconomic status including housing is strongly related to worse health of Roma as compared to the non-Roma population. Rosicova et al. (5) also in a study from Slovakia identified lower education level and higher unemployment as a predictor for higher mortal- ity rates in males of the general population and also identified data gaps in estimating income amongst the Roma population. Vokó et al. (6) in a Hungarian study identified the socioeconomic status as a strong determinant of health in the Roma population and concluded that it may explain worse health in the studied community. Koupilová et al. (7) in their review pointed out that the available studies, with few exceptions, confirm that the health of the Roma community in the Czech Republic and Slovakia is considerably poorer compared to the non-Roma population. Poor hygiene and dietary habits are factors strongly related to adverse health outcomes. Dostal et al. (8) in their study indicated significantly higher morbidity from selected communicable diseases in Roma children under 2 years of age compared to non-Roma children in the same region.

Housing is considered a strong determinant of the population health. The LARES study of the World Health Organization (WHO) (9) showed that housing conditions are related to health and well-being regardless of individual factors. The authors conclude that inadequate housing can be considered a possible 
factor through which poverty can affect health and well-being of population. Housing, as a determinant of health, can negatively directly impact vulnerable and marginalized population groups, such as the Roma population.

Several studies were recently conducted worldwide in developing countries on the quality of indoor air and its impact on the health of inhabitants (10-16). Sundell (17) in his paper reports that at least 2 million deaths annually are attributable to unvented burning of biomass fuels indoors in developing countries. Carbon monoxide, Carbon Dioxide, Particulate Matter, Nitrous Oxide, Sulfur Oxide were the most commonly studied pollutants linked to health outcomes such as respiratory diseases, respiratory symptoms and allergies (13-16, 18-21). A number of studies reported hazardous levels of these pollutants in houses where biomass fuel was used as the primary source for heating and cooking (13, $14,16,18-21)$. Despite the fact that information and data on air quality and health is available from a number of countries and impoverished communities, no such assessment is available from the Roma communities in Central and Eastern Europe.

The objective of this paper is to provide information on indoor air quality and the quality of the broader indoor environment of the houses in Roma villages in Slovakia and Romania and to discuss possible implications for health.

\section{MATERIALS AND METHODS}

\section{Study Sites and Study Populations}

The Roma population in Slovakia and Romania was the principal target population of the study. For the pilot investigation presented in this paper two study sites were selected. Both study sites were a segregated part of the respective major settlements with a majority of Roma inhabitants. In Slovakia, the Roma village of Letanovce was chosen with a population of 767 (total population of the village including the main part was 2,107)*. In Romania, the Roma part of the San Paul village was chosen with the population of 272 Roma (total population of San Paul was 950)**. The availability of Roma assistants who helped the study investigator to access the community was a condition for choice of study sites.

Houses for the study in both study sites were chosen for analysis based on an agreement of the inhabiting family to participate. Access to the houses was granted after detailed explanation about the objectives and scope of the study by the study investigators and the Roma assistant. No randomized sampling strategy was used in selection of houses. Eleven houses were successfully included in the Romanian study site and 19 houses in the Slovakian study site.

\section{Data Collection}

Levels of Carbon Monoxide (CO), Carbon Dioxide $\left(\mathrm{CO}_{2}\right)$, total Particulate Matter (PM), temperature and relative humidity were measured in the enrolled houses. The equipment used for data collection allowed for instant readings of levels of the meas- ured factors (Casella Microdust-pro Real Time Dust Monitor for PM sampling and GrayWolf Indoor Air Quality Meter for CO, $\mathrm{CO}_{2}$, temperature and humidity sampling). The setting of the study sites did not allow for a long-period continuous sampling (e.g. 24 hours or more) due to the lack of electricity outlets in the examined houses and security concerns. Thus, a surrogate method of repeated short-term continuous sampling was applied. All the factors were sampled for a 6 minute period and instant readings of the levels were recorded every 10 seconds. The sampling was repeated approximately after one hour in all houses. Data from both 6 minutes samplings was joined into a single dataset. The sampling took place in the room where the main cooking and heating source was located at approximate breathing zone height.

An environmental questionnaire was used in order to obtain further data on indoor environmental factors such as smoking, pets, ventilation, or cooking and heating materials and habits. An environmental checklist was used by study investigators to assess the indoor environment, building quality and materials used.

The data collection in both study sites was divided into two phases. The first phase took place in the winter season (February 2009 in both sites) and the second phase took place during the summer (June 2009 in both sites). During both phases the same set of houses was analyzed.

\section{Approaches to Analysis and Presentation of Results}

Data from $\mathrm{CO}, \mathrm{CO}_{2}$, temperature and humidity sampling along with information obtained from the environmental questionnaire and checklist were analyzed following three strategies of comparison. Firstly, the houses included in both study sites were compared with each other (e.g. 19 houses from the Slovakian site with each other and 11 houses from the Romanian site with each other). Using this approach, information on within-site variations could be presented. Secondly, the levels of factors measured in houses are presented in the summer versus winter manner. Thus, comparison of between-season variation in the same set of houses was made possible. Thirdly, data are presented to allow comparison between houses in the two study sites (e.g. data from Slovakian set of houses versus Romanian set of houses compared in the same season of the year).

\section{Statistical Analysis}

Medians with inter-quartile ranges (given as intervals) were used as the measure of central tendency of numeric variables. Percentages were used to describe frequencies in case of categorical variables. The two-samples and paired Wilcox test (when comparing two variables) and the Kruskal-Wallis test (when comparing more than two variables) were used to test differences in medians as appropriate. Chi square test or Fisher's exact test (where counts were less than 10) were used to test differences in proportions. Boxplots were used to graphically display the distributions and variations of the measured factors levels. Probability level of $<0.05$ was considered to be statistically significant.

\footnotetext{
* information acquired from the Municipal Office of the Commune of Letanovce, Slovakia.

** information acquired from the Municipal Office of the Commune of San Paul, Romania.
} 


\section{RESULTS}

\section{General Description of Housing Conditions}

Although general housing conditions differed between the study sites, they can be characterized as relatively uniform when considering each site separately. The general build quality of the houses in Romania was better compared to Slovakia. All of them were brick built houses. Most of the houses had more than one room.

In Slovakia, wood was the main building material for the houses. Subsequently, the indoor space was more prone to draft due to worse insulation from the ambient environment. The sealing of doors and windows was generally worse compared to the Romanian site. Most of the houses had one room of an approximate size ranging from 15 to 35 square meters.

The main heating/cooking appliance in both study sites was a metallic oven designed to be fueled by solid fuels, such as wood, coal or other materials. Roofs of all houses were made of tiles or sheet metal on a wooden construction. All houses had a chimney outlet. All houses in both sites used fire wood as the primary fuel. No other type of biomass was observed.

Table 1 summarizes the results of our survey using the environmental questionnaire and the environmental check list. The median number of persons in the households was 4 in both countries. A high proportion of inhabitants spent at least half a day inside the house and is thus exposed to the hazards that are present indoors. In Slovakia, most of the participants perceived their overall indoor environment as dry and dusty, and in Romania, as humid. In Slovakia, the usage of common household waste as a heating fuel was usual in all households. Other appliances, besides biomass cook-stoves, were used, such as natural gas driven furnaces or ovens in less than a half of the households in Slovakia. Ventilation frequency was higher in Romanian houses and in the majority of Slovakian houses the windows were rarely or never opened (some windows could not be opened because they missed a handle). Smoking inside the houses and even in the bedrooms was a very common habit in both countries. Both domestic animals and rodents were commonly reported to be present inside the houses.

\section{Results of Measurements of Specific Pollutants}

Levels of factors monitored in the indoor environment for all houses combined in both countries are compared in Table 2. Higher median concentrations of both Carbon Monoxide and Carbon Dioxide are apparent in both countries in winter. The median temperature in winter was higher in Romania and lower in Slovakia and the relative humidity in winter was higher in Romanian houses and lower in Slovakian houses compared to summer periods. We tested the differences in median levels between winter and summer periods showing statistically significant differences in all comparisons.

Figure 1 shows the comparison of indoor temperatures in all enrolled houses in both countries. In general, in Romanian houses the temperature medians and ranges were higher as compared to the winter period. On the other hand, in Slovakia the pattern was the reverse and the median temperatures were higher during the summer period compared to winter. The median temperatures in summer ranged from $24.6{ }^{\circ} \mathrm{C}$ (IQR $24.5-24.8^{\circ} \mathrm{C}$ ) to $25.8^{\circ} \mathrm{C}$ (IQR 25.6-25.9 ${ }^{\circ} \mathrm{C}$ ) in Romania and from $23.3^{\circ} \mathrm{C}\left(22.7-24^{\circ} \mathrm{C}\right.$ ) to $29.4^{\circ} \mathrm{C}\left(\mathrm{IQR} 28.7-29.8^{\circ} \mathrm{C}\right.$ ) in Slovakia. The median temperatures in winter ranged from $24.3{ }^{\circ} \mathrm{C}$ (IQR $21.7-25.6^{\circ} \mathrm{C}$ ) to $30.3^{\circ} \mathrm{C}$ (IQR $27.5-30.7^{\circ} \mathrm{C}$ ) in Romania and from $12.8^{\circ} \mathrm{C}$ (IQR 9.3-16.2 ${ }^{\circ} \mathrm{C}$ ) to $24.7^{\circ} \mathrm{C}$ (IQR $21.7-26.8^{\circ} \mathrm{C}$ ) in Slovakia. We found statistically significant differences between summer and winter temperatures in all houses and also between countries (e.g. the median temperatures in Romania were significantly different from Slovakia in both summer and winter period).

The relative humidity in the houses displayed in Figure 2 differed significantly in the summer and winter period in all cases in both countries. In general, a pattern of distinctly higher humidity in summer is apparent in Romanian houses. In Slovakian houses this pattern is not so obvious. The highest measured relative humidity in winter was $45.3 \%$ (IQR 39.4-53.7\%) in Romania and $72.2 \%$ (IQR $69.8-73.1 \%$ ) in Slovakia. The highest humidity in

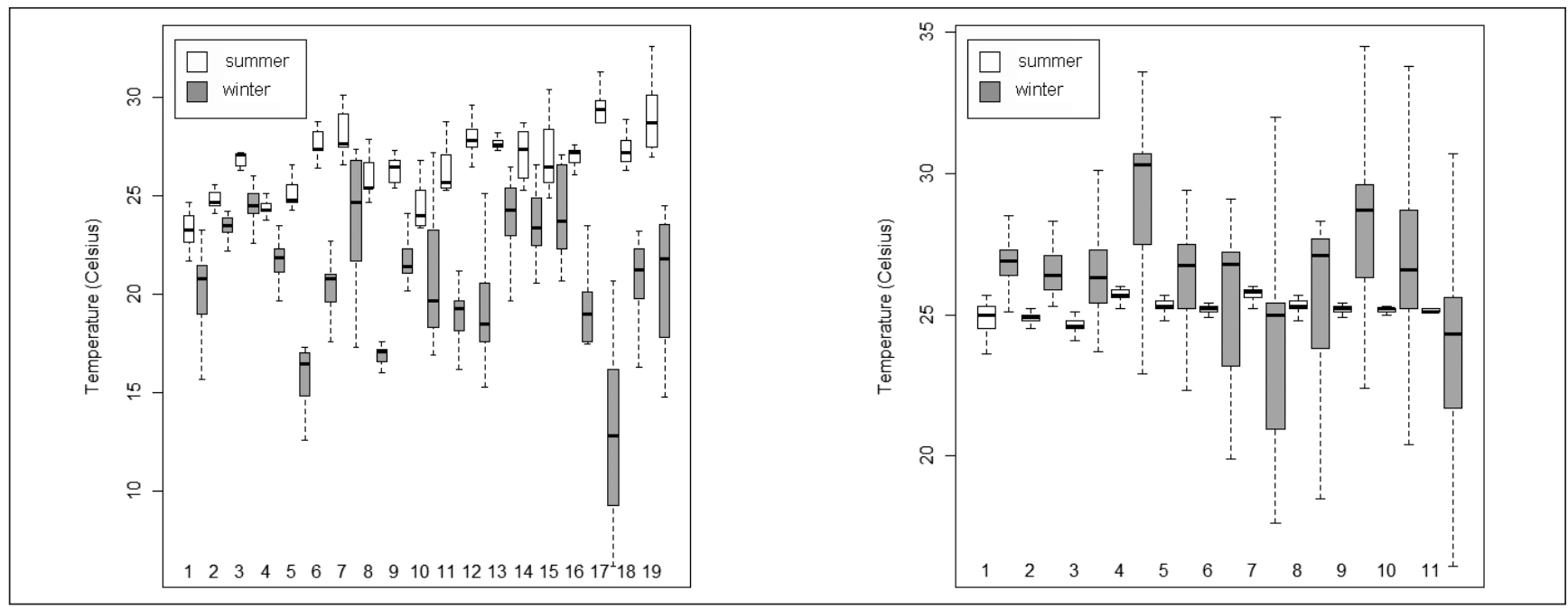

Fig. 1. Temperature in summer and winter period in 19 enrolled houses in Slovakia - left graph vs. 11 houses in Romania right graph ( $p<0.001$ in all summer vs. winter comparisons). 
Table 1. Characterization of the indoor environment and hazards in the examined houses in Slovakia and Romania

\begin{tabular}{|c|c|c|c|c|c|c|c|}
\hline \multirow[t]{2}{*}{ Country } & \multicolumn{2}{|c|}{$\begin{array}{l}\text { Slovakia } \\
(n=19)\end{array}$} & \multicolumn{2}{|c|}{$\begin{array}{c}\text { Romania } \\
(n=11)\end{array}$} & \multicolumn{2}{|c|}{$\begin{array}{c}\text { Total } \\
(n=30)\end{array}$} & \multirow[t]{2}{*}{$\mathrm{p}$-value } \\
\hline & $\mathrm{N}$ & $\%$ & $\mathrm{~N}$ & $\%$ & $\mathrm{~N}$ & $\%$ & \\
\hline Persons in household (median) & 4 & & 4 & & 4 & & \\
\hline \multicolumn{8}{|l|}{ Time spend inside } \\
\hline Half a day & 18 & 95 & 7 & 64 & 25 & 83 & \multirow{2}{*}{$<0.05$} \\
\hline The whole day & 1 & 5 & 4 & 36 & 5 & 17 & \\
\hline \multicolumn{8}{|l|}{ Indoor air quality } \\
\hline Humid air & 6 & 32 & 3 & 27 & 9 & 30 & n.s. \\
\hline Dry air & 9 & 47 & 0 & 0 & 9 & 30 & $<0.05$ \\
\hline Dusty & 9 & 47 & 0 & 0 & 9 & 30 & $<0.05$ \\
\hline \multicolumn{8}{|l|}{ Primary heating and cooking fuel } \\
\hline Local wood heating & 0 & 0 & 11 & 100 & 11 & 37 & \multirow{2}{*}{$<0.001$} \\
\hline Wood + waste heating & 19 & 100 & 0 & 0 & 19 & 63 & \\
\hline \multicolumn{8}{|l|}{ Secondary appliance for heating } \\
\hline Gas furnace & 8 & 42 & 0 & 0 & 8 & 27 & $<0.05$ \\
\hline \multicolumn{8}{|l|}{ Secondary appliance for cooking } \\
\hline Gas furnace & 7 & 37 & 0 & 0 & 7 & 23 & \multirow{2}{*}{$<0.05$} \\
\hline Stove for solid fuel & 12 & 63 & 11 & 100 & 23 & 77 & \\
\hline \multicolumn{8}{|l|}{ Draft problems } \\
\hline Never & 0 & 0 & 5 & 45 & 5 & 17 & \multirow{3}{*}{$<0.05$} \\
\hline Often & 5 & 26 & 3 & 27 & 8 & 27 & \\
\hline Always & 14 & 74 & 3 & 27 & 17 & 57 & \\
\hline \multicolumn{8}{|l|}{ Open windows for ventilation } \\
\hline Never & 11 & 58 & 0 & 0 & 11 & 37 & \multirow{4}{*}{$<0.01$} \\
\hline Once a week & 5 & 26 & 0 & 0 & 5 & 17 & \\
\hline Every day & 3 & 16 & 4 & 36 & 7 & 23 & \\
\hline More than once a week & 0 & 0 & 7 & 64 & 6 & 20 & \\
\hline \multicolumn{8}{|l|}{ Smoking in household } \\
\hline No & 1 & 5 & 0 & 0 & 1 & 3 & \multirow{3}{*}{$<0.05$} \\
\hline Occasionally & 8 & 42 & 0 & 0 & 8 & 27 & \\
\hline Frequently & 10 & 53 & 11 & 100 & 21 & 70 & \\
\hline \multicolumn{8}{|l|}{ Smoking in bedrooms } \\
\hline Never & 2 & 11 & 0 & 0 & 2 & 7 & \multirow{4}{*}{$<0.05$} \\
\hline Sometimes & 8 & 42 & 0 & 0 & 8 & 27 & \\
\hline Frequently & 9 & 47 & 11 & 100 & 20 & 67 & \\
\hline No. of cigarettes smoked inside (median) & 30 & & 20 & & 20 & & \\
\hline \multicolumn{8}{|l|}{ Pets, rodents } \\
\hline Mice & 16 & 84 & 5 & 45 & 21 & 70 & $<0.05$ \\
\hline Rats & 18 & 95 & 0 & 0 & 18 & 60 & $<0.001$ \\
\hline Dog inside & 10 & 53 & 0 & 0 & 10 & 33 & $<0.01$ \\
\hline
\end{tabular}

summer was 62.3\% (IQR 60.9-63.2\%) in Romania and 64.3\% (IQR 63.7-64.8\%) in Slovakia.

In Figure 3, we summarize the results of the total particulate matter sampling in the examined houses. Our analysis shows that the levels were in general higher in Romanian houses compared to Slovakian ones. The median concentrations ranged from $0.21 \mathrm{mg} /$ $\mathrm{m}^{3} \operatorname{IQR}\left(0.14-0.31 \mathrm{mg} / \mathrm{m}^{3}\right)$ to $1.35 \mathrm{mg} / \mathrm{m}^{3}$ (IQR $\left.1.19-1.56 \mathrm{mg} / \mathrm{m}^{3}\right)$ in Slovakian houses and from $0.17 \mathrm{mg} / \mathrm{m}^{3}$ (IQR $0.09-0.49 \mathrm{mg} /$ $\mathrm{m}^{3}$ ) to $0.69 \mathrm{mg} / \mathrm{m}^{3}$ (IQR $0.29-1.28 \mathrm{mg} / \mathrm{m}^{3}$ ) in Romanian houses. The total median levels combined for all houses were $0.48 \mathrm{mg} /$ $\mathrm{m}^{3}$ (IQR $0.25-0.79 \mathrm{mg} / \mathrm{m}^{3}$ ) for Slovakia and $0.41 \mathrm{mg} / \mathrm{m}^{3}$ (IQR $\left.0.19-0.76 \mathrm{mg} / \mathrm{m}^{3}\right)$ for Romania $(\mathrm{p}<0.05)$. 
Table 2. Comparison of levels of indoor environmental factors in all houses between summer and winter in both countries

\begin{tabular}{|l|c|c|c|c|c|c|}
\hline \multirow{2}{*}{$\begin{array}{l}\text { Indoor } \\
\text { environmental factor }\end{array}$} & \multicolumn{2}{|c|}{ Slovakia } & \multirow{2}{*}{$p$-value } & \multicolumn{2}{|c|}{ Romania } & \multirow{2}{*}{$p$-value } \\
\cline { 2 - 3 } \cline { 5 - 6 } & Winter sampling & Summer sampling & & Winter sampling & Summer sampling \\
\hline $\begin{array}{l}\text { Carbon Monoxide } \\
\text { median (IQR) } \\
\mathrm{mg} / \mathrm{m}^{3}\end{array}$ & $2.4(1.7-3.5)$ & $0.65(0.4-1)$ & $<0.001$ & $4.9(3.6-7.2)$ & $2.6(2.1-3)$ & $<0.001$ \\
\hline $\begin{array}{l}\text { Carbon Dioxide } \\
\text { median (IQR) } \\
\mathrm{mg} / \mathrm{m}^{3}\end{array}$ & $2,543(2,123-3,399)$ & $1,324(1,138-1,487)$ & $<0.001$ & $2,805(2,329-3,321)$ & $2,127(1,925-2,242)$ & $<0.001$ \\
\hline $\begin{array}{l}\text { Temperature } \\
\text { median (IQR) } \\
{ }^{\circ} \mathrm{C}\end{array}$ & $21.3(18.7-23.6)$ & $26.7(24.8-27.5)$ & $<0.001$ & $26.6(25.1-28)$ & $25.2(25-25.4)$ & $<0.001$ \\
\hline $\begin{array}{l}\text { Relative Humidity } \\
\text { median (IQR) } \\
\%\end{array}$ & $44.2(39.7-50.2)$ & $41.2(37.4-46.8)$ & $<0.001$ & $38.5(35.1-43.1)$ & $55.6(54.5-56.8)$ & $<0.001$ \\
\hline
\end{tabular}

IQR - Interquartile range
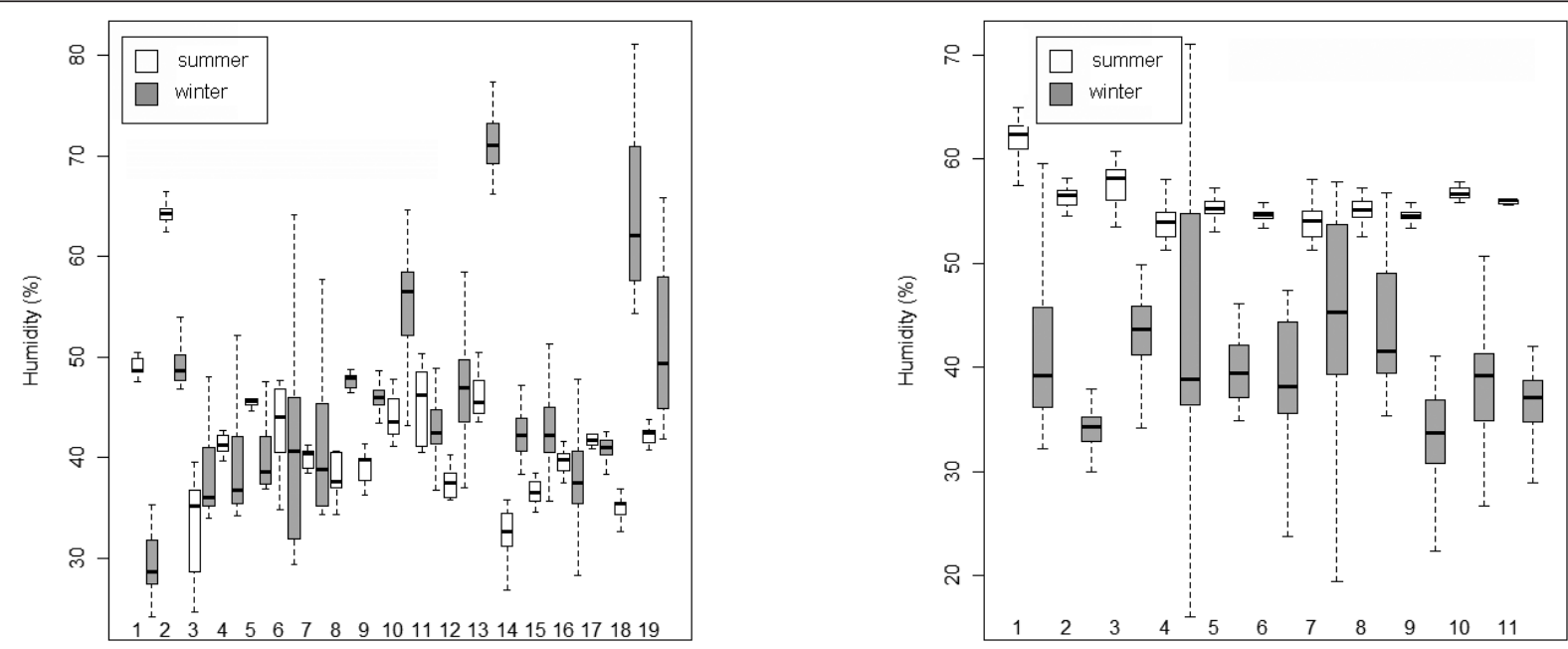

Fig. 2. Humidity in summer and winter period in 19 enrolled houses in Slovakia - left graph vs. 11 houses in Romania - right graph ( $p<0.001$ in all summer vs. winter comparisons).

Carbon Monoxide levels in the houses are reported in Figure 4. Due to the known toxicity of this gas and the fact that the public health authorities set a limit value for 8 hour exposure in low category housing (22), we have compared our findings against this limit value. Notably, a clear trend of higher concentrations in winter compared to summer is apparent in both countries. In Romania, the CO levels in two houses exceeded the $10 \mathrm{mg} / \mathrm{m}^{3}$ limit value and in two houses the levels were close to this limit. In Slovakia, two of the houses exceeded this limit in winter, although in one of the houses only the upper end of the range on measured concentrations exceeded the limit. In winter, the highest observed levels were 17.8 $\mathrm{mg} / \mathrm{m}^{3}$ (IQR $17.4-24.7 \mathrm{mg} / \mathrm{m}^{3}$ ) in Romania and $19.7 \mathrm{mg} / \mathrm{m}^{3}$ (IQR $19.4-20.8 \mathrm{mg} / \mathrm{m}^{3}$ ) in Slovakia. On the other hand, in summer the highest levels in Romania were $3.5 \mathrm{mg} / \mathrm{m}^{3}$ (IQR $3.3-3.6 \mathrm{mg} / \mathrm{m}^{3}$ ) and in Slovakia $2.6 \mathrm{mg} / \mathrm{m}^{3}$ (IQR $2.2-3 \mathrm{mg} / \mathrm{m}^{3}$ ). In our statistical analysis we showed a significant difference $(p<0.001)$ between summer and winter concentrations in all houses in both countries and a significantly higher level in Romanian houses compared to Slovakian houses (comparing all houses combined in both countries) in both summer and winter $(\mathrm{p}<0.001)$.
Similar to Carbon Monoxide levels, we have observed a pattern of higher levels in winter compared to summer in Carbon Dioxide levels (Fig. 5) in all houses both in Romania and Slovakia. The highest median winter concentration observed in Slovakia was $4,049 \mathrm{mg} / \mathrm{m}^{3}$ (IQR 3,501-4,501 mg/m $\mathrm{m}^{3}$ ) and in Romania 3,551 mg/ $\mathrm{m}^{3}$ (IQR 2,849-4,313 mg/m $\mathrm{m}^{3}$ ). On the other hand, in our repeated measurements in the summer we found $798 \mathrm{mg} / \mathrm{m}^{3}$ (IQR 765-863 $\left.\mathrm{mg} / \mathrm{m}^{3}\right)$ as the highest median level in Slovakia and $1,896 \mathrm{mg} /$ $\mathrm{m}^{3}\left(1,795-2,303 \mathrm{mg} / \mathrm{m}^{3}\right)$ in Romania. The differences between summer and winter levels were significant in all houses in both countries $(\mathrm{p}<0.001)$.

\section{DISCUSSION}

\section{Overall Indoor Environment}

In general, the quality of the examined households indoor environment was poor in many aspects. All households used biomass (i.e. fire wood) as a primary fuel for heating and cook- 


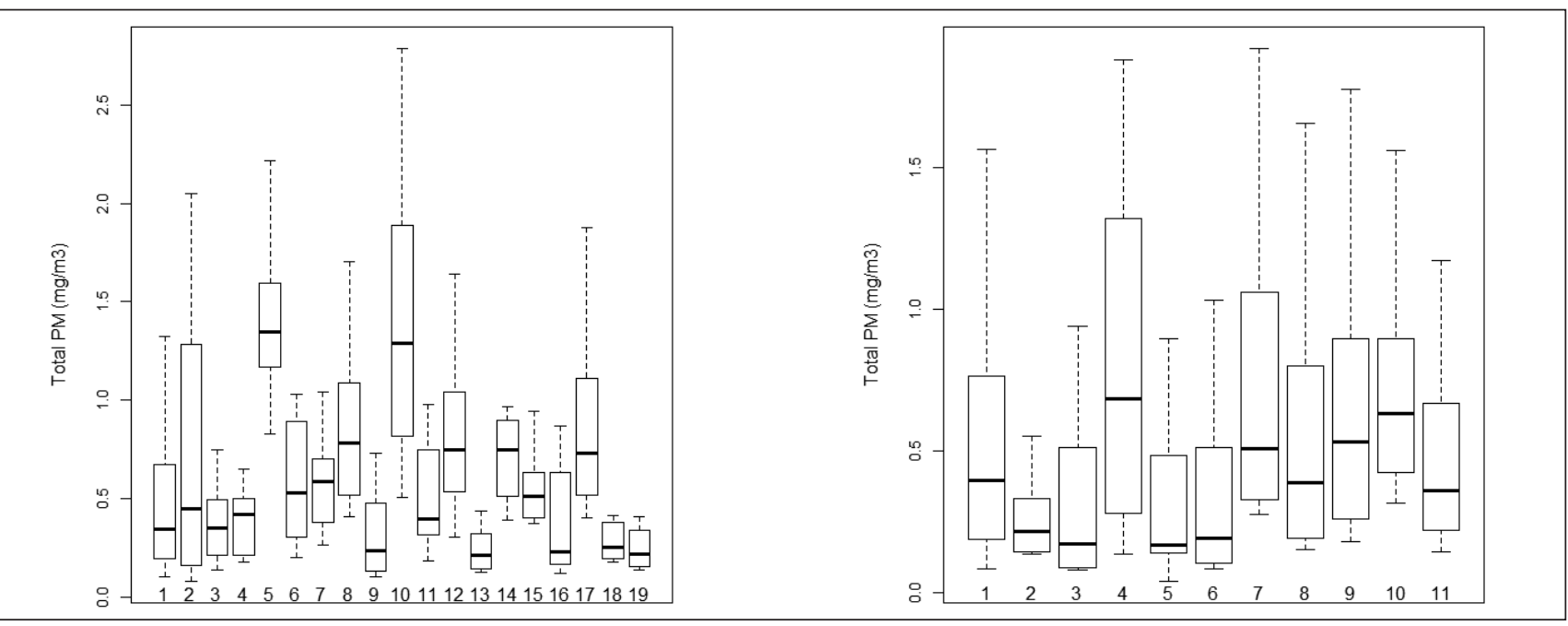

Fig. 3. Levels of total particulate matter (PM) in 19 enrolled houses in Slovakia - left graph vs. 11 houses in Romania - right graph.

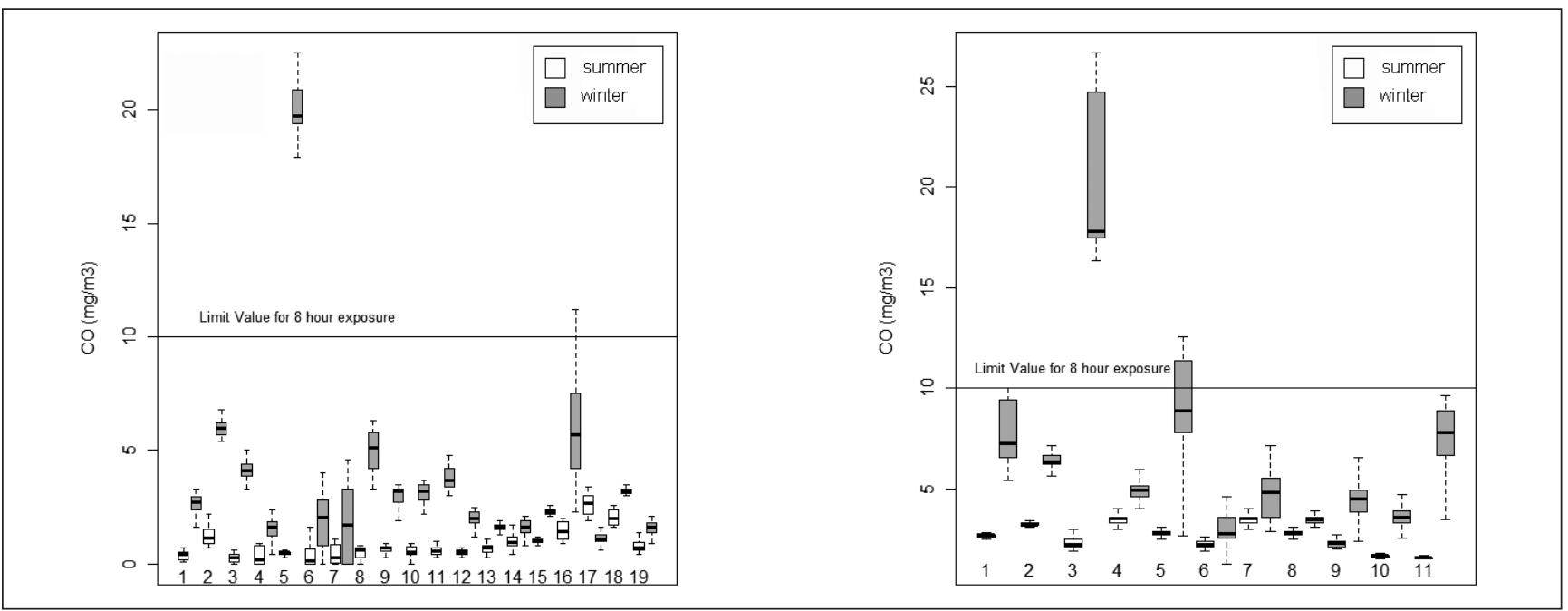

Fig. 4. Levels of Carbon Monoxide (CO) in summer and winter period in 19 enrolled houses in Slovakia - left graph vs. 11 houses in Romania - right graph ( $p<0.001$ in all summer vs. winter comparisons).

ing purposes. A study by Lissowska et al. (23) conducted in the majority population of Slovakia reports that wood or coal was used in less than $50 \%$ of households for cooking and in less than $65 \%$ for heating (gas and electricity was preferred) - unlike in the Roma houses in our study. Kvakova (24) reported use of biomassdriven stoves in $50 \%$ of the rural Slovakian households sampled and in less than $10 \%$ of urban households. The self-perceived quality of the indoor air tended to be poor as well. One of the main factors of the self-reported discomfort was the perception of draft inside the houses. This was reportedly present even when doors and windows were closed. Thus, we can assume that the main cause of draft was insufficient sealing of windows and doors caused by poor materials. Kvakova (24) reports self-perceived draft problems in less than $20 \%$ of urban and less than $50 \%$ of rural households. Considering the presence of other potentially harmful factors such as smoking indoors, pets or rodents inside the houses, and insufficient ventilation habits - the overall indoor environment of Roma houses could be described as poor and potentially hazardous for health. Our findings also suggest that in the indoor environment of the houses in Roma villages in
Slovakia some hazards are more prevalent and so it tends to be poorer than the indoor environment of urban or rural houses in the majority population of Slovakia.

\section{Level of Specific Pollutants}

In our study we have assessed the indoor air levels of Carbon Monoxide (CO), Carbon Dioxide $\left(\mathrm{CO}_{2}\right)$, total PM, temperature and relative humidity. $\mathrm{PM}, \mathrm{CO}$, and $\mathrm{CO}_{2}$ have been linked to biomass usage in a number of recent studies (10-12, 14, 16-21, 23, 25-27). In some studies, additional pollutants were sampled,such as endotoxin (12), nitric oxides $(13,14)$, sulfur dioxide $(14,27)$, and the 2.5 micrometer fraction of the PM $(18,20)$.

Carbon Monoxide is one of the most hazardous products of biomass combustion. Clark et al. (18) reported a mean concentration of $17.6 \mathrm{mg} / \mathrm{m}^{3}$ in houses with traditional stoves in their study from Honduras, Padhi et al. (14) in their study from biomassusing houses in rural India reported a mean level of $0.987 \mathrm{mg} /$ $\mathrm{m}^{3}$. Siddiqui et al. (11) in their study in Pakistan observed a mean concentration of $36.4 \mathrm{mg} / \mathrm{m}^{3}$. The median levels in our study in 

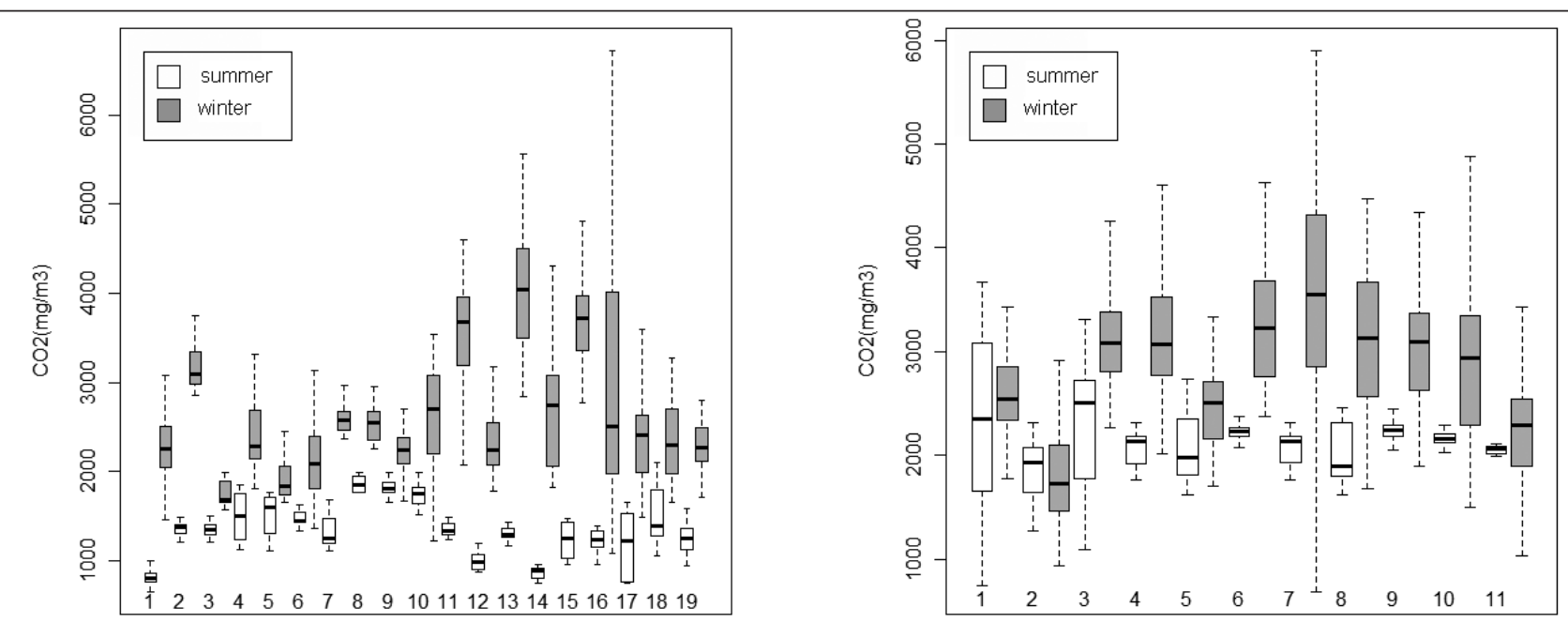

Fig. 5. Levels of Carbon Dioxide ( $\left.\mathrm{CO}_{2}\right)$ in summer and winter period in 19 enrolled houses in Slovakia - left graph vs. 11 houses in Romania - right graph ( $p<0.001$ in all summer vs. winter comparisons).

winter were $2.4 \mathrm{mg} / \mathrm{m}^{3}$ (IQR $1.7-3.5 \mathrm{mg} / \mathrm{m}^{3}$ ) in Slovakia and $4.9 \mathrm{mg} / \mathrm{m}^{3}$ (IQR $3.6-7.2 \mathrm{mg} / \mathrm{m}^{3}$ ) in Romania. The levels were significantly lower in summer being $0.65 \mathrm{mg} / \mathrm{m}^{3}$ (IQR $0.4-1 \mathrm{mg} /$ $\mathrm{m}^{3}$ ) in Slovakia and $2.6 \mathrm{mg} / \mathrm{m}^{3}$ (IQR $2.1-3 \mathrm{mg} / \mathrm{m}^{3}$ ) in Romania. Compared to findings of other studies in different populations and environments, the levels of CO from our samplings were lower. This might be caused by differences in the biomass fuel used, type of stove (even use of open fire), different quality build of houses or different building materials used. However, considering that most of our study subjects spent at least a half of an average day indoors, such levels can potentially be seriously hazardous for health. Similar to CO levels, we have also measured significantly higher concentrations of $\mathrm{CO}_{2}$ in winter than in summer in both countries. These findings suggest that the levels of pollutants, and thus the exposure rates, are higher in winter than in summer possibly due to heating during the winter period, less ventilation and more time spent inside.

The median levels of total PM were $0.48 \mathrm{mg} / \mathrm{m}^{3}$ (IQR 0.25 $0.79 \mathrm{mg} / \mathrm{m}^{3}$ ) in Slovakian houses and $0.41 \mathrm{mg} / \mathrm{m}^{3}$ (IQR 0.19-0.76 $\left.\mathrm{mg} / \mathrm{m}^{3}\right)$ in Romanian houses $(\mathrm{p}<0.05)$. Rosati et al. (12) in their study reports mean levels of total PM ranging from 2 to $7 \mathrm{mg} /$ $\mathrm{m}^{3}$, Hakim (27) estimates the average value at $0.052 \mathrm{mg} / \mathrm{m}^{3}$. The limit value set by health authorities in Slovakia is $0.05 \mathrm{mg} / \mathrm{m}^{3}$ of particles of 10 micrometers in size for a 24 hour exposure (22). Most similar studies used continuous monitoring and sampled the respirable fractions of PM rather than total PM to indicate exposure to PM $(11,12,16,25)$. Although such an approach was not possible in our study settings, in future studies all efforts should be made to employ it.

\section{Health Implications}

As suggested by other authors it is rather complex and difficult to define causal relationships between indoor air pollutants and health outcomes for a variety of methodological or data validity issues $(17,18,21,28)$. It is not possible to establish causal exposure-health effect relationships based on our data, which was not the primary objective of this paper. However, several possible health implications emerge from the published work on similar topics. Clearly, not all results from other studies can be applied to the Roma population because of differences in the studied population, methods and study settings used. Fullerton et al. (19) in their extensive review conclude that use of biomass fuels indoors generates exposure to a range of indoor pollutants which increases the incidence of respiratory infections, chronic obstructive pulmonary disease, low birth-weight, cataracts, cardiovascular events as well as all-cause mortality both in adults and children. In addition to these health effects, Zhang et al. (21) in their review of studies from China reported reduced lung function, weakening of immune system or lung cancer also to be associated with such exposures. Bruce et al. (25) stated that diseases from such exposures contribute significantly to the global burden of disease especially by an increase in children's acute lower respiratory infections.

Although based on our data, there is no clear evidence that such health effects are present in the Roma population in Central Eastern Europe, the information drawn from studies from across the world suggests that particular attention should be paid to indoor air pollution. Parekh et al. (29) in their review emphasized the need for prioritizing Roma as a specific community for public health action. Our data suggests that the indoor environment can be considered an important determinant of health in this community. Our findings might be helpful in generating hypotheses for further research in this field.

\section{Limitations of the Study and Suggestions for Future Research}

The Roma community in Central and Eastern Europe differs from the non-Roma population in its surrounding areas in many aspects (culture, beliefs, and habits). Such differences may pose barriers in accessing and involving the community in research studies as well as in obtaining valid data and information from study subjects. Our team had to adjust the methods of the presented study due to such barriers and difficulties. Koupilová et al. (7) in a review came to the conclusion that it can be complicated to conduct epidemiological studies in communities culturally different from the majority. Amongst other reasons they list traditional 
distrust in authorities, or considering health related matters as being private and not to be discussed outside the family. Hajioff et al. (1) report that research in the Roma community has to be culturally-sensitive and should recognize the social and political context of this society. Zeman et al. (2) in their review emphasize the importance of understanding and respecting the organization and structure of the Roma community and the importance of gaining their respect.

To gain access to the studied communities we have used Roma assistants. In both countries these persons came from the respective Roma community and were government employees. In addition, the local priest and school teachers helped to access the community of San Paul in Romania. Their role in the study was crucial and we suggest their use in future studies in this community.

Most recent studies causally linking exposure to biomass related pollutants indoors to health outcomes use a 24 hour period for continuous sampling of the indoor air $(10,13,19,20,26)$. Although we are aware that continuous sampling is the method of choice in this type of study, the setting in our study sites did not allow for this. Unavailable electricity outlets in the houses, lack of human resources as well as lack of willingness to participate in a 24 hour sampling cycle posed significant barriers and forced us to use a surrogate method. Another drawback is that no reliable data was recorded for the outdoor meteorological conditions. Although the relationship between the ambient and indoor conditions was not the principal interest of this study, such data may bring clues when assessing and describing the indoor environment and its dynamics. We suggest recording such data in future research in this field.

Questionnaires, in addition to population surveys, personal health documentations or databases of health authorities are common tools in obtaining data on health of inhabitants of households enrolled in studies similar to ours $(10-21,26)$. In our study, we attempted to use the respiratory questionnaire of the American Thoracic Society (30) to assess the respiratory health symptoms. We have experienced problems with comprehension of the questionnaire items from the side of the participants which might be caused by a low health literacy level in this community. Recall bias was another issue present in our interviews. Based on these issues we concluded that the data obtained using the questionnaire lacks validity and thus we decided not to use it for assessing the respiratory health of our subjects. For future studies we would suggest using instruments other than self-reported health assessments.

Spirometry examination was another way we attempted to assess the respiratory health. However, similarly to the questionnaire interviews, we experienced a lack of comprehension from the side of the subjects and the results are not valid enough to be used in the presented paper.

As a consequence of the mentioned limitations, our study samples in both study sites were relatively low and a bias is imposed on our findings. Therefore, no causal relationship or conclusion should be drawn based on our results.

Despite the unfavourable consequences of the aforementioned issues for our findings and results, we believe that they can serve as valuable information for future research in the Roma communities and as a lead in designing feasible studies and interventions.

\section{CONCLUSIONS}

Although there is no clear evidence that health effects caused by exposure to pollutants from biomass burning are present in the Roma population in Central and Eastern Europe, the findings of our study suggest that particular attention should be paid to indoor air quality in Roma communities by health authorities as well as researchers.

Further studies arise as a necessity in order to clearly evaluate the situation. A larger and randomized sample with a reliable health outcome measure is needed to establish causal relationships. In designing future studies, attention must be paid to the cultural and socioeconomic background of the Roma community and the methods and tools used should be considered carefully in context of their usability and feasibility.

Indoor air pollution in Roma settlements has a strong potential to be a serious threat to health. Interventions involving health education, increasing health literacy and the introduction of the use of improved technologies and novel energy sources may improve the indoor air quality and reduce the health risks from exposures to pollutants in the indoor environment.

\section{Acknowledgements}

This project was supported by NIH Research Grant No. D43 TW000621 from the Fogarty International Center. The content is solely the responsibility of the authors and does not necessarily represent the official views of the Fogarty International Center or the National Institutes of Health. We would like to thank the community workers in both study sites, students from the Trnava University in Slovakia and the Babes Bolyai University in Romania for their help during the field works. We are grateful to Professor Wayne Sanders of the University of Iowa for his valuable input and help in creating the methodology and study protocol for this research. We would like to thank Monica O'Mullane, $\mathrm{PhD}$ of Trnava University for the English language editing. We are grateful to members of the field teams in Romania and Slovakia, especially: Miroslav Svaro, Marek Psota, Alexandra Brizaniuc and the Roma assistants in both study sites for their kind help with data collection and with helping to access the community for the purposes of this research.

\section{REFERENCES}

1. Hajioff S, McKee M. The health of the Roma people: a review of the published literature. J Epidemiol Community Health. 2000 Nov;54(11):864-9.

2. Zeman CL, Depken DE, Senchina DS. Roma health issues: a review of the literature and discussion. Ethn Health. 2003 Aug;8(3):223-49.

3. Kósa Z, Széles G, Kardos L, Kósa K, Németh R, Országh S, et al. A comparative health survey of the inhabitants of Roma settlements in Hungary. Am J Public Health. 2007 May;97(5):853-9.

4. Skodova Z, van Dijk JP, Nagyova I, Rosenberger J, Ondusova D, Studencan M, et al. Psychosocial factors of coronary heart disease and quality of life among Roma coronary patients: a study matched by socioeconomic position. Int J Public Health. 2010 Oct;55(5):373-80.

5. Rosicova K, Geckova AM, van Dijk JP, Rosic M, Zezula I, Groothoff JW. Socioeconomic indicators and ethnicity as determinants of regional mortality rates in Slovakia. Int J Public Health. 2009;54(4):274-82.

6. Vokó Z, Csépe P, Németh R, Kósa K, Kósa Z, Széles G, et al. Does socioeconomic status fully mediate the effect of ethnicity on the health of Roma people in Hungary? J Epidemiol Community Health. 2009 Jun;63(6):455-60.

7. Koupilová I, Epstein H, Holcík J, Hajioff S, McKee M. Health needs of the Roma population in the Czech and Slovak Republics. Soc Sci Med. 2001 Nov;53(9):1191-204. 
8. Dostal M, Topinka J, Sram RJ. Comparison of the health of Roma and non-Roma children living in the district of Teplice. Int J Public Health. 2010 Oct;55(5):435-41.

9. World Health Organization. Large analysis and review of European housing and health status (LARES): preliminary overview. Copenhagen: WHO Regional Office for Europe; 2007.

10. Dasgupta S, Huq M, Khaliquzzaman M, Pandey K, Wheeler D. Indoor air quality for poor families: new evidence from Bangladesh. Indoor Air. 2006 Dec;16(6):426-44.

11. Siddiqui AR, Lee K, Bennett D, Yang X, Brown KH, Bhutta ZA, et al. Indoor carbon monoxide and PM2.5 concentrations by cooking fuels in Pakistan. Indoor Air. 2009 Feb;19(1):75-82.

12. Rosati JA, Yoneda KY, Yasmeen S, Wood S, Eldridge MW. Respiratory health and indoor air pollution at high elevation. Arch Environ Occup Health. 2005 Mar-Apr;60(2):96-105.

13. Kumie A, Emmelin A, Wahlberg S, Berhane Y, Ali A, Mekonnen E, et al. Magnitude of indoor NO2 from biomass fuels in rural settings of Ethiopia. Indoor Air. 2009 Feb;19(1):14-21.

14. Padhi BK, Padhy PK. Domestic fuels, indoor air pollution, and children's health. Ann N Y Acad Sci. 2008 Oct;1140:209-17.

15. Rehfuess E, Mehta S, Prüss-Ustün A. Assessing household solid fuel use: multiple implications for the Millennium Development Goals. Environ Health Perspect. 2006 Mar;114(3):373-8.

16. Rumchev K, Spickett JT, Brown HL, Mkhweli B. Indoor air pollution from biomass combustion and respiratory symptoms of women and children in a Zimbabwean village. Indoor Air. 2007 Dec;17(6):468-74.

17. Sundell J. On the history of indoor air quality and health. Indoor Air. 2004;14 Suppl 7:51-8.

18. Clark ML, Peel JL, Burch JB, Nelson TL, Robinson MM, Conway S, et al. Impact of improved cookstoves on indoor air pollution and adverse health effects among Honduran women. Int J Environ Health Res. 2009 Oct;19(5):357-68.

19. Fullerton DG, Bruce N, Gordon SB. Indoor air pollution from biomass fuel smoke is a major health concern in the developing world. Trans $\mathrm{R}$ Soc Trop Med Hyg. 2008 Sep;102(9):843-51.
20. Gao X, Yu Q, Gu Q, Chen Y, Ding K, Zhu J, et al. Indoor air pollution from solid biomass fuels combustion in rural agricultural area of Tibet, China. Indoor Air. 2009 Jun;19(3):198-205.

21. Zhang JJ, Smith KR. Household air pollution from coal and biomass fuels in China: measurements, health impacts, and interventions. Environ Health Perspect. 2007 Jun;115(6):848-55.

22. Edict of the Ministry of Health of Slovakia No. 259/2008 on the requirements on indoor environment of buildings and on the minimal requirements on flats of lower standard and accomodation facilities. Zbierka zákonov SR. 2008; čiastka 105:2142-62.

23. Lissowska J, Bardin-Mikolajczak A, Fletcher T, Zaridze D, SzeszeniaDabrowska N, Rudnai P, et al. Lung cancer and indoor pollution from heating and cooking with solid fuels: the IARC international multicentre case-control study in Eastern/Central Europe and the United Kingdom. Am J Epidemiol. 2005 Aug 15;162(4):326-33.

24. Kvakova M. Indoor air quality and health in urban and rural areas in Slovakia [dissertation]. Trnava: Trnava University; 2011.

25. Bruce N, Perez-Padilla R, Albalak R. Indoor air pollution in developing countries: a major environmental and public health challenge. Bull World Health Organ. 2000;78(9):1078-92.

26. Edwards RD, Liu Y, He G, Yin Z, Sinton J, Peabody J, et al. Household $\mathrm{CO}$ and PM measured as part of a review of China's National Improved Stove Program. Indoor Air. 2007 Jun;17(3):189-203.

27. Hakim AK, Kharboush IF, Naguib KK, Mortada MM, Noweir KH, El Araby II. Indoor air pollution and acute lower respiratory infections in the first two years of life. J Egypt Public Health Assoc. 1995;70(5-6):661-78.

28. Holcátová I. Health effects of indoor air pollutants - difficulties of evaluation. Cent Eur J Public Health. 1999 Feb;7(1):50-1.

29. Parekh N, Rose T. Health inequalities of the Roma in Europe: a literature review. Cent Eur J Public Health. 2011 Sep;19(3):139-42.

30. Ferris BG. Epidemiology Standardization Project (American Thoracic Society). Am Rev Respir Dis. 1978 Dec;118(6 Pt 2):1-120.

Received August 31, 2011 Accepted in revised form May 14, 2012 